\title{
In vivo silencing of alpha-synuclein using naked siRNA
} Jada Lewis* ${ }^{* 1}$, Heather Melrose ${ }^{\dagger 1}$, David Bumcrot ${ }^{2}$, Andrew Hope ${ }^{1,5}$, Cynthia Zehr ${ }^{1}$, Sarah Lincoln ${ }^{1}$, Adam Braithwaite ${ }^{1}$, Zhen He ${ }^{1}$, Sina Ogholikhan ${ }^{1}$, Kelly Hinkle ${ }^{1}$, Caroline Kent ${ }^{1}$, Ivanka Toudjarska ${ }^{2}$, Klaus Charisse ${ }^{2}$, Ravi Braich², Rajendra K Pandey², Michael Heckman ${ }^{3}$, Demetrius M Maraganore ${ }^{4}$, Julia Crook ${ }^{3}$ and Matthew J Farrer ${ }^{1}$

Address: ${ }^{1}$ Department of Neuroscience, Mayo Clinic, 4500 San Pablo Road, Jacksonville, FL 32224, USA, ${ }^{2}$ Alnylam Pharmaceuticals, 300 3rd St, Cambridge, MA 02142, USA, ${ }^{3}$ Department of Biostatistics, Mayo Clinic, 4500 San Pablo Road, Jacksonville, FL 32224, USA, ${ }^{4}$ Department of Neurology, Mayo Clinic, 200 1st St SW, Rochester, MN 55905, USA and 5ReNeuron, 10 Nugent Road, Surrey Research Park, Guildford, Surrey, GU2 7AF, UK

Email: Jada Lewis* - lewis.jada@mayo.edu; Heather Melrose - melrose.heather@mayo.edu; David Bumcrot - dbumcrot@alnylam.com; Andrew Hope - Andrew-Hope@reneuron.com; Cynthia Zehr - zehrcindy@hotmail.com; Sarah Lincoln - lincoln.sarah@mayo.edu; Adam Braithwaite - atb001@gmail.com; Zhen He - Zhen.He@fda.hhs.gov; Sina Ogholikhan - sinao@ufl.edu;

Kelly Hinkle - hinkle.kelly@mayo.edu; Caroline Kent - kent.caroline@mayo.edu; Ivanka Toudjarska - itoudjarska@alnylam.com; Klaus Charisse - kcharisse@alnylam.com; Ravi Braich - rbraich@anylam.com; Rajendra K Pandey - rpandey@alnylam.com; Michael Heckman - Heckman.Michael@mayo.edu; Demetrius M Maraganore - dmaraganore@mayo.edu; Julia Crook -Crook.Julia@mayo.edu; Matthew J Farrer - farrer.matthew@mayo.edu

* Corresponding author †Equal contributors

Published: I November 2008

Molecular Neurodegeneration 2008, 3:19 doi:10.1186/1750-1326-3-19
Received: 13 August 2008

Accepted: I November 2008

This article is available from: http://www.molecularneurodegeneration.com/content/3/1/19

(C) 2008 Lewis et al; licensee BioMed Central Ltd.

This is an Open Access article distributed under the terms of the Creative Commons Attribution License (http://creativecommons.org/licenses/by/2.0), which permits unrestricted use, distribution, and reproduction in any medium, provided the original work is properly cited.

\begin{abstract}
Background: Overexpression of $\alpha$-synuclein (SNCA) in families with multiplication mutations causes parkinsonism and subsequent dementia, characterized by diffuse Lewy Body disease postmortem. Genetic variability in SNCA contributes to risk of idiopathic Parkinson's disease (PD), possibly as a result of overexpression. SNCA downregulation is therefore a valid therapeutic target for PD.

Results: We have identified human and murine-specific siRNA molecules which reduce SNCA in vitro. As a proof of concept, we demonstrate that direct infusion of chemically modified (naked), murine-specific siRNA into the hippocampus significantly reduces SNCA levels. Reduction of SNCA in the hippocampus and cortex persists for a minimum of I week post-infusion with recovery nearing control levels by 3 weeks post-infusion.

Conclusion: We have developed naked gene-specific siRNAs that silence expression of SNCA in vivo. This approach may prove beneficial toward our understanding of the endogenous functional equilibrium of SNCA, its role in disease, and eventually as a therapeutic strategy for $\alpha$ synucleinopathies resulting from SNCA overexpression.
\end{abstract}




\section{Background}

The importance of $\alpha$-synuclein in the pathogenesis of Parkinson's disease (PD) initially emerged in 1997 when Polymeropoulos and colleagues reported that a missense A53T mutation in the $\alpha$-synuclein gene (SNCA) causes familial parkinsonism in four seemingly unrelated kindreds [1]. Subsequently, SNCA A30P and E46K missense mutations were found to cause familial Lewy Body parkinsonism [2,3]. The importance of the $\alpha$-synuclein protein (non-amyloid component precursor; NACP) was confirmed through its recognition as a major component of both Lewy bodies, the pathological hallmark of PD and dementia with Lewy bodies (DLB), and of glial cytoplasmic inclusions in multiple system atrophy (MSA) [4].

In addition to missense mutations, multiplication of the normal SNCA locus can cause familial PD. Singleton et al. first reported genomic triplication of the SNCA locus in affected family members with early onset, parkinsonism, with subsequent cognitive dysfunction [5]. Post-mortem exam revealed profound neuronal loss in the substantia nigra (SN) and widespread Lewy pathology from the cortex to the basal ganglia [6,7]. Additional de novo SNCA duplications and triplications have since been reported in French, Japanese, Korean and Swedish-American families [8-14]. Functionally, SNCA multiplications result in a copy-number related increase in both $\alpha$-synuclein RNA and protein $[8,15]$, and disease onset and severity are associated with gene dosage [11]. Taken together, this provides compelling evidence that SNCA overexpression can result in Lewy body parkinsonism and dementia.

Although SNCA multiplication remains a rare cause of inherited PD, common genetic variability in the SNCA locus is a risk factor for idiopathic PD [16-18]. The effects may be mediated by elevated mRNA/protein expression $[8,15,19,20]$. Hence therapy aimed at reducing SNCA expression levels may provide therapeutic benefit for patients with either familial or idiopathic PD.

The use of double-stranded RNAs for the silencing of genes was first accomplished in nematodes [21]. Molecules of 21 and 22 nucleotides had the most activity in Drosophila, and these reagents were named short interfering (si)RNAs [22]. siRNA induces the formation of an RNA-induced silencing complex (RISC) which acts as an endonuclease on target RNA [23], yielding a powerful tool which can be used to reduce expression of specific genes. To exploit the therapeutic potential of siRNA, we developed naked siRNA molecules against SNCA that are resistant to endo- and exonuclease activity in serum and yield species-specific reduction of SNCA in vitro. We then injected them into the Cornu Ammonis (CA1) of the hippocampus of mice and demonstrated a reduction in SNCA mRNA levels by quantitative reverse transcription- polymerase chain reaction (RT-PCR) and in situ hybridization throughout the hippocampus and cortex. Additionally, we have demonstrated that $\alpha$-synuclein protein expression in these same cells is qualitatively reduced. This protocol will be invaluable for improving our understanding of the in vivo dynamics of $S N C A$, assessing the impact of $S N C A$ silencing in the pathogenesis of animal models of $\mathrm{PD}$, and perhaps may hold promise as a future neuroprotective therapy for PD in humans.

\section{Methods}

\section{In vitro characterization of siRNA}

Detailed method for in vitro studies including siRNA synthesis, cell culture and transfection conditions, fluorescent microscopy, RNA and protein analysis and siRNA serum stability analysis are detailed in the additional files section.

\section{In vivo delivery of siRNA}

All rodent procedures were approved by the Mayo Clinic Institutional Animal Care and Use Committee (IACUC), were in accordance with the National Institute of Health Guide for the Care and Use of Laboratory Animals (NIH Publications No. 80-23, revised 1996) and were performed under the supervision of an institutional veterinarian. Mice were allowed unrestricted access to food and water and were supplemented with gelatin containing (32 $\mathrm{mg} / \mathrm{ml}$ ) acetaminophen from 24 hours prior to surgery until 48 hours post-surgery to minimize pain. The day prior to surgery, Alzet osmotic pumps (model 1002, Durect, Inc., Cupertino, CA) were filled to capacity with siRNA against SNCA or luciferase at a concentration of 2 $\mathrm{mM}$ in phosphate buffered saline (PBS). Pumps containing only PBS were prepared for an additional control group. Mice were anaesthetized with tribromoethanol $(200 \mathrm{mg} / \mathrm{kg})$ and stereotaxic surgery was performed to implant a $3 \mathrm{~mm}$ cannula at $-1.5 \mathrm{~mm}$ posterior and -2.0 $\mathrm{mm}$ lateral from bregma and $2.5 \mathrm{~mm}$ deep by the insertion of 2 spacers $(0.25 \mathrm{~mm}$ each) to target the CA1 of the right hippocampus in each 2-month old $\mathrm{C} 57 \mathrm{BL} / 6$ female mice [24]. Cannulae were secured to the skull using Loctite adhesive (Durect, Inc., Cupertino, CA). Mice were allowed to recover from the anesthesia under a heat lamp. SNCA siRNA, luciferase siRNA or PBS was infused at a rate of $0.25 \mu \mathrm{l} /$ hour over 15 days using Alzet osmotic pumps attached to $3 \mathrm{~mm}$ brain infusion cannulae (Alzet brain infusion kit 3, Durect, Inc., Cupertino, CA; http:// www.alzet.com/products/brainkits.php). Following 15 days infusion, brain tissue was harvested from the 2 week $(2 \mathrm{~W})$ cohorts while cannulae were removed on day 15 in cohorts that were allowed to age one week ( $2 \mathrm{~W}-1 \mathrm{~W})$, two weeks $(2 \mathrm{~W}-2 \mathrm{~W})$ or three weeks $(2 \mathrm{~W}-3 \mathrm{~W})$ after the cessation of infusion. At harvest, osmotic pumps were recovered. Mice in which the pump had failed or in which the tubing had become disconnected from the pump were 
included in study groups and in statistical analysis; however, for graphical purposes, the data points for these mice were denoted by distinct symbols when compared to mice in which the pumps were intact and functional. Experiments detailed in Figures 1, 2 and 3 were performed on independent cohorts of mice.

\section{Taqman qRT-PCR analysis of SNCA levels}

For Taqman analysis, the hippocampus was rapidly removed from each hemisphere of the brain and snap-frozen on dry ice in separate tubes. In each case, the right hippocampus represented the injected side (SNCA siRNA, luciferase siRNA, or PBS) and the left hippocampus was utilized as an untreated control. RNA was extracted by phenol extraction using the TRIzol Reagent (Invitrogen; Carlsbad, CA) with the manufacturer's standard protocol.
cDNA was then synthesized using the High Capacity cDNA Archive Kit (Applied Biosystems; Foster City, CA). The following probes were purchased from ABI: GAPDH (Mm99999915_g1), HPRT (Mm01545399_m1), SNCA (Mm00447333_m1), and SNCB (Mm00504325_m1). Quantitative RT-PCR was performed on an ABI 7900 HT using a 384 well plate with quadruple sample replicates. Results were analyzed using SDS v.2.2 software and the expression data was normalized to mouse GAPDH and HPRT. Resulting graphs and data were generated using GraphPad Prism v.4 software (GraphPad Software Inc., La Jolla, CA).

\section{In situ analysis of SNCA and SNCB levels}

To ensure sampling consistency, the brain was placed in a tissue matrix and the region anterior and posterior to the

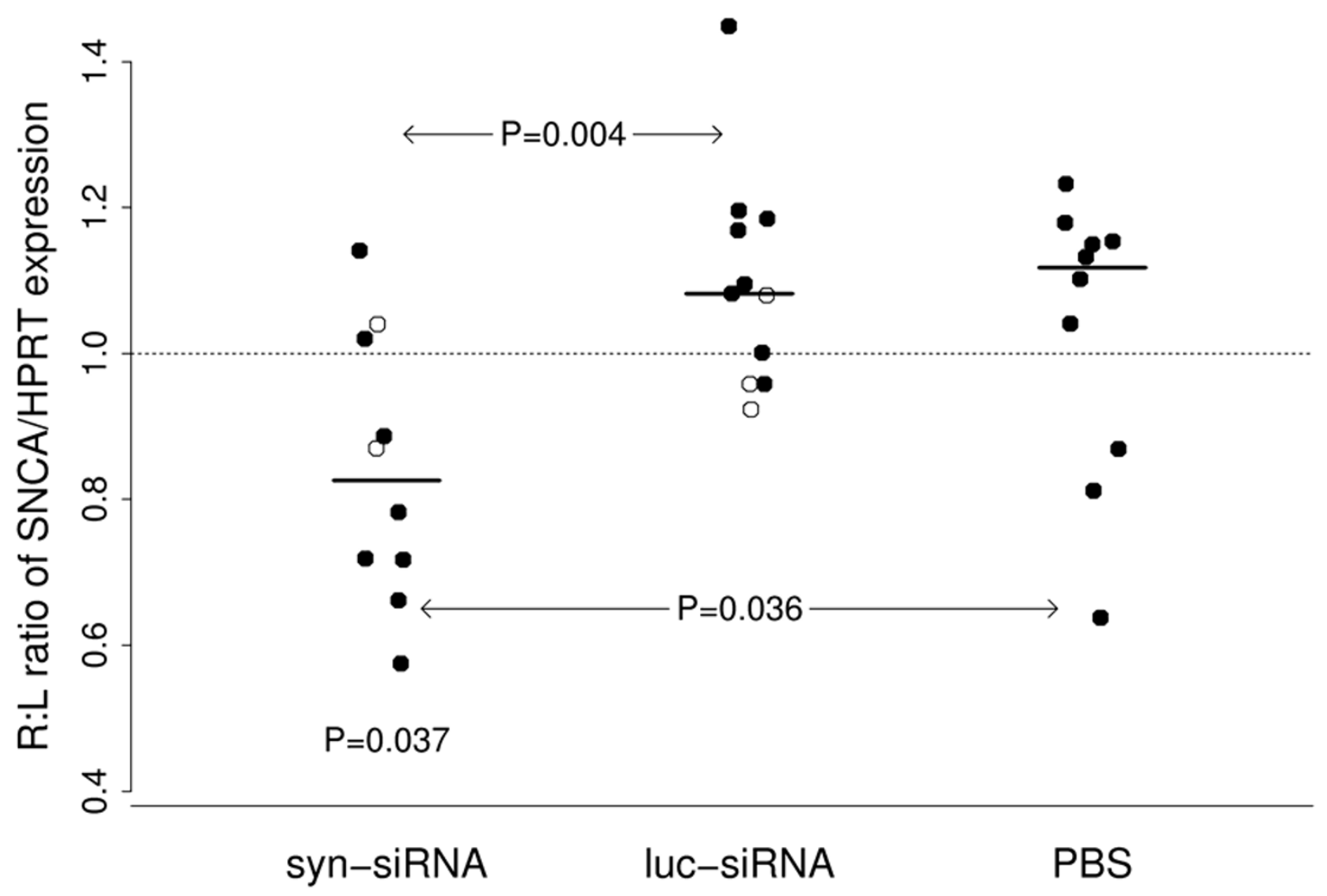

Figure I

qRT-PCR analysis of SNCA expression following in vivo RNAi.SNCA siRNA (syn-siRNA), luciferase siRNA (luc-siRNA), or PBS was infused into the right CAI. qRT-PCR was used to determine expression of SNCA following RNAi in treated right side compared to the untreated contralateral side (R:L ratio). SNCA siRNA had a statistically significant decrease of SNCA expression in the right compared to the left side of the brain, and $R: L$ ratios were decreased when compared to controls (vs PBS, $p=0.036$; vs. luciferase, $p=0.004)$. Horizontal lines show medians. Open circles indicate mice in which the cannula was disconnected during treatment or did not function. 

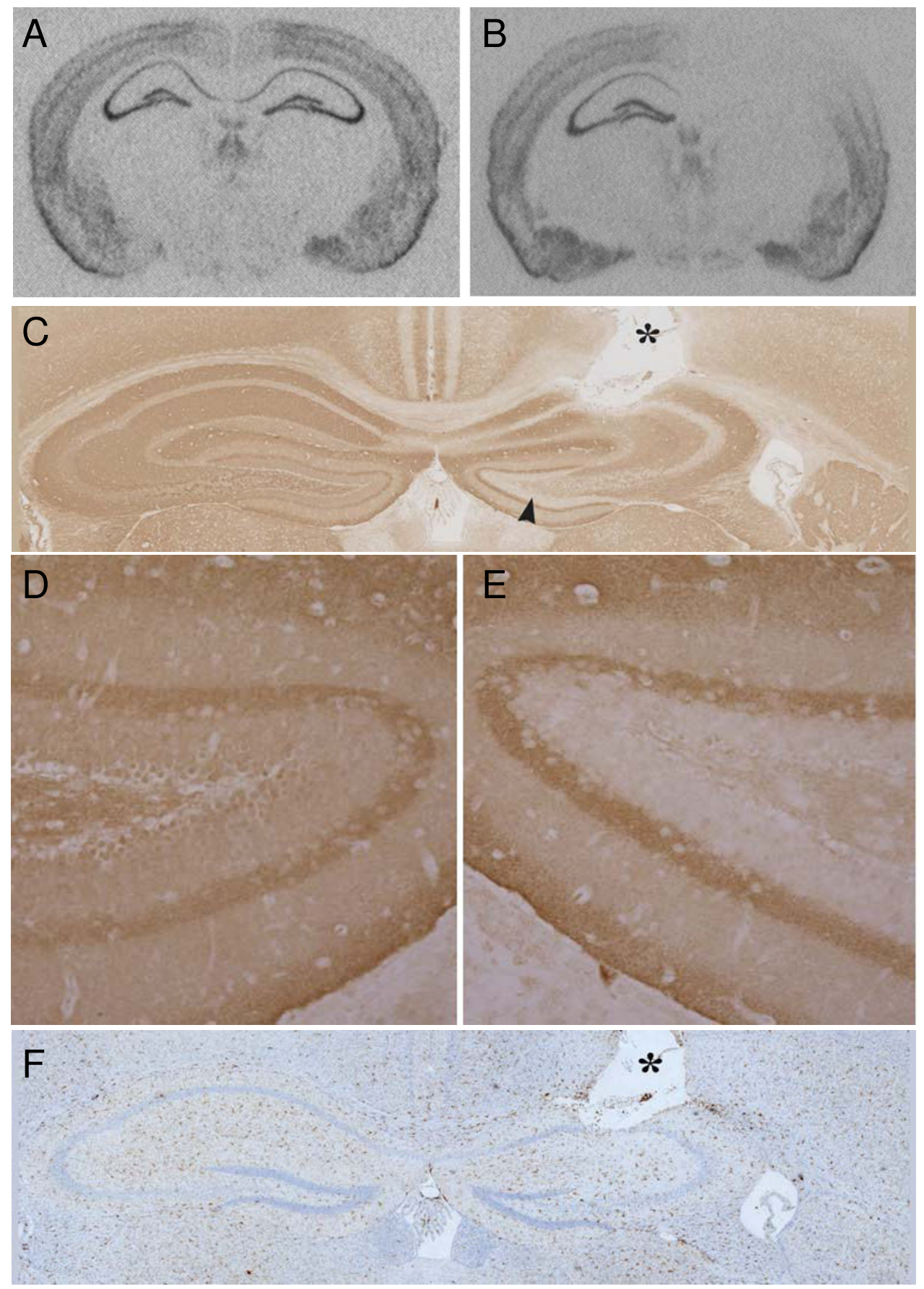

\section{Figure 2}

RNA and protein analysis of $\alpha$-synuclein expression following in vivo SNCA siRNA treatment. The right CAI was infused with either PBS, siRNA to luciferase, or siRNA against our SNCA target. A typical SNCA in situ from an animal treated with (A) PBS or (B) SNCA siRNA on the right side compared to the uninjected left sides. While the cannula tract was evident in the right hippocampi of the infused mice $(*$ in $C$ and F), regardless of treatment group, (C) immunostaining for $\alpha$-synuclein demonstrates considerable knockdown of protein expression (arrowhead) in the hippocampus when the uninjected control side is compared to the SNCA siRNA-treated side, also shown in higher magnification (D, E), respectively. (F) Inflammatory changes, as shown by lba-I immunostaining for microgliosis, were minimal around the infusion site. Sample brain in (F) showed the highest degree of damage from infusion, in this case from SNCA siRNA. 
A

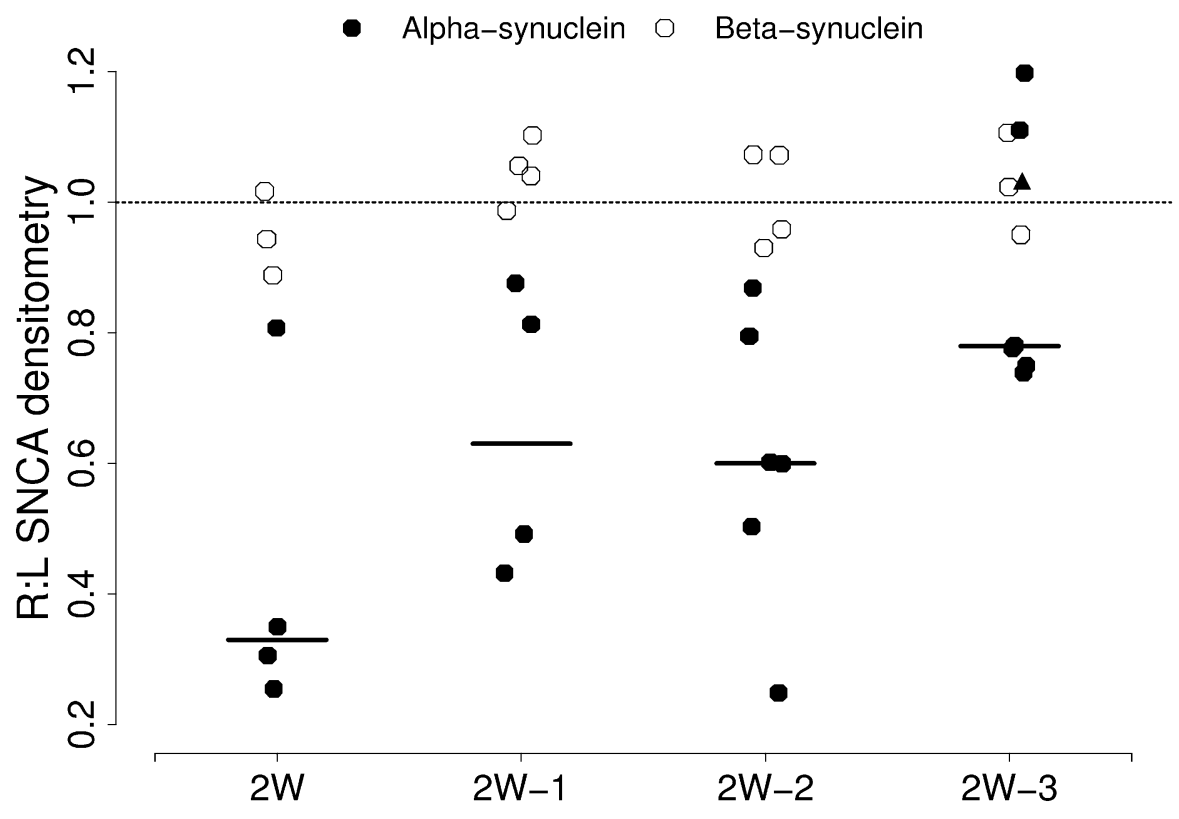

B

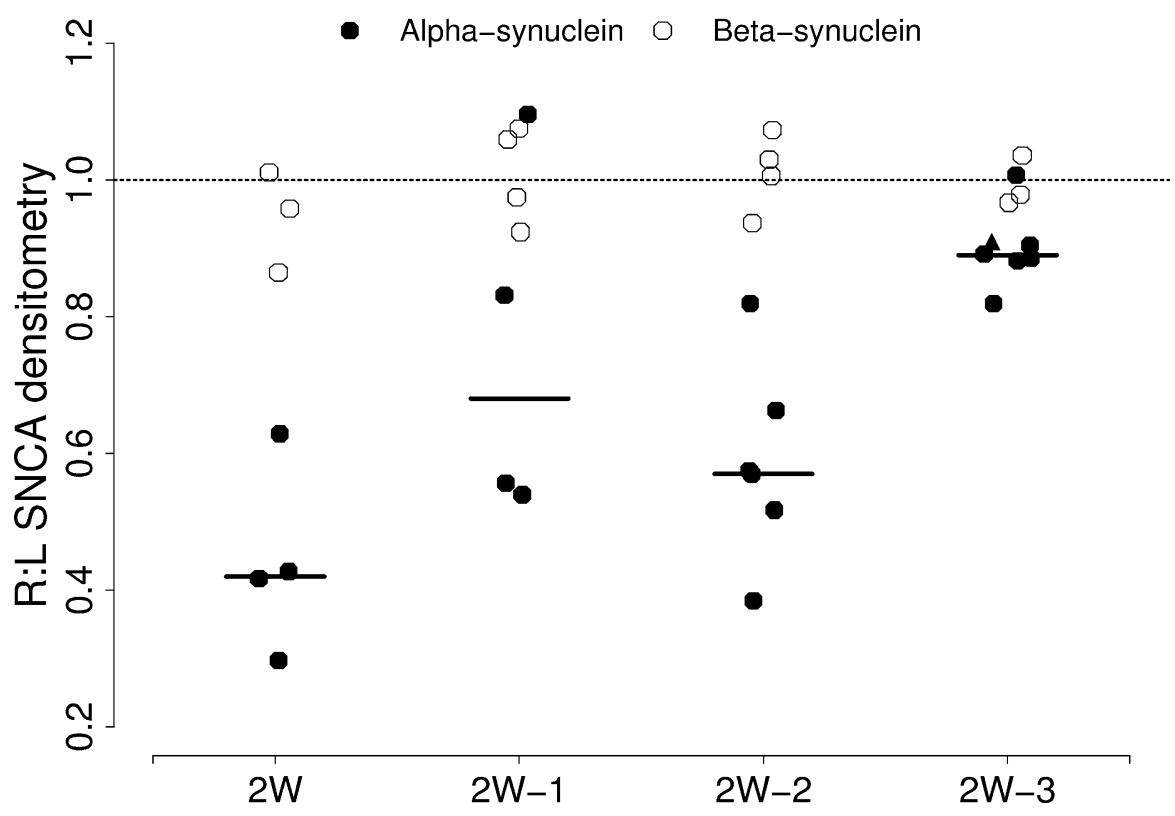

\section{Figure 3}

Silencing of SNCA is resilient and target-specific.SNCA and SNCB expression was assessed by in situ hybridization following extended timecourse of in vivo SNCA siRNA treatment. Qualitative densitometric analysis was performed on mice treated with SNCA siRNA on the right side of the brain and a ratio showing either SNCA or SNCB expression in the treated (R) and untreated (L) brain was calculated and plotted for each animal within a group. The knockdown of SNCA expression (black circle) persists in the (A) CAI and the (B) cortex two weeks after cannula removal with SNCA approaching normal levels by three weeks post-infusion. The closed triangle indicates SNCA levels in a mouse in which the cannula was loose at the end of the study. Non-specific silencing of SNCB (open circle) was not observed at any timepoint. 
hippocampus was removed using a flat blade. The resulting three brain segments were snap frozen on dry ice and stored at $-80^{\circ} \mathrm{C}$ until use. $15 \mu \mathrm{m}$ thick frozen sections were cut on a cryostat at $-18^{\circ} \mathrm{C}$ throughout the entire hippocampus and air dried for 20 minutes before freezing at $-80^{\circ} \mathrm{C}$. Frozen sections were removed on dry ice and dried quickly on a slide warmer at $55^{\circ} \mathrm{C}$, fixed in $4 \%$ paraformaldehyde in 0.1 M Sorensen's Phosphate buffer for 20 minutes, washed twice in PBS and dehydrated in ascending alcohols. Hybridization was performed at $37^{\circ} \mathrm{C}$ overnight in a moist chamber, with approximately $0.02 \mathrm{ng}$ of $\left[\alpha-{ }^{33} \mathrm{P}\right]$ dATP (Perkin Elmer, Waltham, MA, USA) 3' end labeled probe per $1 \mu$ l of hybridization buffer $(4 \times$ sodium chloride/sodium citrate (SSC), $1 \times$ Denhardt's solution, $50 \%(\mathrm{w} / \mathrm{v})$ de-ionised formamide, $10 \%(\mathrm{w} / \mathrm{v})$ dextran sulphate, $200 \mathrm{mg} / \mu \mathrm{l}$ herring sperm DNA). The SNCA probe (5'GGTCTTCTCAGCCACTGTTGTCACTCCATGAAC-

CAC'3) was designed to exon 3. The beta-synuclein (SNCB) probe was designed to the 3' untranslated region (UTR) (5'CAGACAGATTGGCTTTATTCATGGACACACT-

GGG'3). Specific activity of the probe was at least $1 \times 10^{8}$ counts per minute $(\mathrm{cpm}) / \mu \mathrm{g}$, and after dilution in hybridization buffer corresponded to $\sim 1 \times 10^{4} \mathrm{cpm} / \mu \mathrm{l}$. Control hybridizations contained a 50-fold molar excess of unlabelled probe to determine non-specific signal. Slides were washed in $1 \times \mathrm{SSC}$ at room temperature (RT) to remove excess hybridization buffer; three times at $55^{\circ} \mathrm{C}$ for 30 minutes per wash and at RT for 60 minutes. Slides were then dipped for 30 seconds in $70 \%$ (v/v) ethanol $/ 300 \mathrm{mM}$ ammonium acetate, then for 30 seconds in absolute alcohol, air dried and co-exposed with ${ }^{12} \mathrm{C}$ microscale standards (Amersham, Piscataway, NJ) to Biomax MS film (Kodak, Rochester, NY) for 7-10 days.

Densitometric analysis of the images was performed using a micro computing imaging device and MCID Elite v.7 software (MCID, Imaging Research Inc., Ontario, Canada). Sections which were anatomically asymmetrical, damaged or in which the hippocampus was not visible were not included in the analysis. Five matching areas for analysis were outlined on the left and right hemispheres of each section: cortex including retrosplenial agranular cortex, primary and secondary motor cortex; hippocampus CA1; CA2; CA3; and dentate gyrus (DG) including polymorph layer DG. Optical density readings were calibrated to the ${ }^{12} \mathrm{C}$ microscale standards to give radioactivity quantities in $\mathrm{nCi} / \mu \mathrm{g}$. SNCA densitometry was measured in cortex, CA1, CA2, CA3, and dentate gyrus of the treated (right) side of the brain and compared to corresponding regions in the untreated (left) side in two to four sections per animal.

\section{Immunohistochemistry}

$5 \mu \mathrm{m}$ paraffin sections were de-waxed, hydrated and washed in PBS. Endogenous peroxidases were blocked in
$0.3 \%$ hydrogen peroxide in PBS. To allow epitope unmasking, sections stained for activated microglia with Iba-1 were steamed in distilled water for 30 minutes. Unmasking was not required for $\alpha$-synuclein. Non-specific sites were blocked with 5\% non-fat milk in PBS for 30 minutes. Sections were then incubated for 1 hour at RT with a mouse IgG1 anti- $\alpha$-synuclein antibody (1:500 dilution, clone 42, BD Biosciences, San Jose, CA) or rabbit Iba-1 antibody (1:1000 dilution, Wako Chemicals USA, Richmond, VA) in 5\% non-fat milk. Control slides were set up without primary antibody. Sections were then washed in PBS twice for five minutes and then incubated with anti-mouse biotinylated secondary antibody (Vector Laboratories, Burlingame, CA, USA). After washing, sections were then incubated with Vectastain $A B C^{\circledast}$ reagent in PBS according to the manufacturer's instructions. Signal was visualized with DAB (3',3' diaminobenzidine, Vector Laboratories).

\section{Statistical analysis}

Statistical analysis for in vitro studies utilized the t-test to compare groups; Welch's modified t-test was used when variances differed. Numerical variables were summarized with the sample median, $25^{\text {th }}$ percentile, and $75^{\text {th }}$ percentile. The Wilcoxon signed rank sum test was used to test whether the median right/left (R:L) ratio of SNCA expression from quantitative RT-PCR differed from 1 . The Wilcoxon rank sum test was used to compare qRT-PCR SNCA expression between siRNA and control mice groups; it was also used to compare SNCA densitometry R:L ratio between groups of mice. Graphical exploration was used to investigate trends in SNCA densitometry R:L brain region ratio over different timepoints. Statistical significance was determined at the 5\% level.

\section{Results and discussion \\ Screening for active siRNAs in vitro}

We initially designed nine siRNAs (Mayo 1-9) which are complementary to the SNCA transcript in the coding region and the 3 '-UTR region (Additional file 1 ). These siRNAs were screened for their ability to silence the expression of a transiently co-transfected enhanced green fluorescent protein-human SNCA fusion construct (pEGFP-NACP) in BE(2)-M17 human neuroblastoma cells. Controls included siRNAMr, specific for the enhanced green fluorescence protein (EGFP) portion of the conjugate, and cells transfected with plasmid DNA in the absence of siRNA. Mayo 2, 7 and 8 were found to produce $\geq 89 \%$ silencing (Additional file 2 ). The controls did not display significant silencing $(<43 \%)$. In the absence of plasmid co-transfection, quantitative RT-PCR showed that the endogenous SNCA mRNA transcript was reduced by $89 \%$ for Mayo 2, 52\% for Mayo 7 and 67\% for Mayo 8 (Additional file 3 ). In immunoblots endogenous $\alpha$-synuclein protein showed a $45 \%, 55 \%$ or $53 \%$ knockdown for 
Mayo 2, 7 and 8 respectively (Additional file 3). As opposed to Mayo 7 and Mayo 8, Mayo 2 siRNA diverged from $S N C B$ sequence at only four bases; therefore, we demonstrated that Mayo 2 did not silence the closely related endogenous $S N C B$ transcript (Additional file 4). To further test the species specificity of Mayo 2, 7 and 8, co-transfection of siRNAs was performed with either human or murine SNCA-pEGFP plasmid. Silencing of human SNCA versus murine SNCA was $74 \%$ and $79 \%$ respectively for Mayo2, whereas Mayo 7 and 8 were more human specific ( $85 \%$ human and $47 \%$ mouse for Mayo 7 and $73 \%$ human and $7 \%$ mouse for Mayo 8 . (Additional file 4)

Since siRNAs can be readily degraded in vivo, assays in human serum were performed using modified Mayo 7 and 8 siRNAs (containing either phosphothiorate linkages or 2'-O-methyl substitutions) and enhanced stability was observed (Additional file 5). Modified siRNAs were re-tested for silencing of endogenous SNCA transcript and were found to have maintained their efficacy. A modified version of human specific Mayo8 (Mayo8S2) was selected as the best candidate based on its stability and silencing properties but for in vivo testing in mice it was necessary to modify it to complement murine SNCA mRNA (Mayo8S2M). In vitro testing with either human or murine pEGFP plasmid followed by immunoblot analysis, demonstrated $97 \%$ silencing of the murine $\alpha$-synuclein protein and only $23 \%$ of the human $\alpha$-synuclein protein (Additional file 6).

\section{Specific in vivo knockdown of murine SNCA}

In order to test the ability of naked siRNA to reduce SNCA expression in vivo, we identified the hippocampus and the cortex as having the highest expression of SNCA in the murine brain (data not shown). We subsequently chose to target siRNA against SNCA expression in the hippocampus to decrease variability in our measurements that could be introduced when dissecting out smaller, less defined structures. We delivered Mayo8S2M siRNA against murine SNCA, siRNA against luciferase (luc), or PBS into the right CA1 of the hippocampi of wild-type C57BL6 female mice. Infusions were performed on these inbred female mice to reduce variability that can be introduced by combining genders or by having genetically heterogeneous backgrounds. Continuous infusion of the siRNA or PBS solutions was performed over a period of 15 days with Alzet mini pumps connected to cannulae which were surgically implanted into the right CA1. After 15 days, two pumps containing the SNCA siRNA and three pumps containing the luc siRNA had disconnected. These mice, represented by open circles, are included in the data analysis in Figure 1. The left CA1 was not injected and was therefore utilized for an untreated control. Hippocampal infusion of the Mayo8S2M siRNA resulted in significant knockdown of SNCA when assessed by Taqman quantitative real-time PCR. Normalization was performed against HPRT and GAPDH as endogenous controls. Quantitative RT-PCR analysis demonstrated that SNCA expression was significantly decreased in the right (treated) hippocampus of animals which have received SNCA siRNA when compared to the left (untreated) hippocampus ( $\mathrm{p}=0.037)$ as demonstrated by the R:L ratio of SNCA expression. Additionally, the SNCA-specific siRNA reduced SNCA expression when compared to luciferase-siRNA $(\mathrm{p}=0.004)$ and PBS $(p=0.036)$ treated control mice (Figure 1$)$.

Although SNCA expression was significantly reduced in the SNCA siRNA treated hippocampi, we hypothesized that the efficacy of the siRNA in the brain might be underestimated due to partial diffusion of the siRNA into the contralateral hippocampus. In order to address this issue, we endeavored to examine the distribution of SNCA knockdown by in situ hybridization so that the extent of $S N C A$ reduction could be fully appreciated. Utilizing a mouse SNCA specific probe, we determined if the knockdown of SNCA expression extended beyond the CA1 cannulation site (Figure 2). SNCA knockdown with SNCA siRNA was observed an average of $2.67 \mathrm{~mm} \pm 0.57 \mathrm{~mm}$ from the cannula tip. While the cannulation tract was evident in the infused animals, in general, little damage nor increase in inflammation (Figure 2C, D, E) was noted at the site of infusion regardless of treatment group, and no animals were removed from the study due to hippocampal damage. Figure $2 \mathrm{~F}$ shows the hippocampus from the mouse with the most damage at the infusion site. Ratios were calculated for each animal between the treated (right) side (SNCA siRNA, luc siRNA, and PBS) and the untreated (left) side and then compared across each of the three groups (Table 1). The least reduction in SNCA levels, shown as a reduction in right (R):left (L) ratio, was observed in the cortex $(71 \%$ between PBS and SNCA siRNA treated animals, $\mathrm{p}=0.067$ ), likely reflecting the fact that the cortex spans from regions adjacent to the infusion site to regions quite distant from the infusion site and thus less likely to be affected by the siRNA. Significant reductions in SNCA levels were observed in the CA1 $(66 \%, \mathrm{p}<$ $0.001)$, CA2 (59\%, p < 0.001), CA3 (77\%, p < 0.001), and dentate gyrus $(81 \%, \mathrm{p}=0.001)$ when SNCA siRNA treated animals were compared to PBS treated animals. Similar results were obtained when SNCA siRNA treated animals were compared to luc siRNA treated control mice. Reduction in SNCA levels was confirmed by immunostaining for murine $\alpha$-synuclein protein (Figure 2C and 2D). Notably, $\alpha$-synuclein levels in the cell bodies of the hippocampus were decreased, while $\alpha$-synuclein in projections from distal regions persisted. Toluidine Blue staining of in situ sections showed that decreased SNCA levels in mice treated with SNCA siRNA were not due to neuronal loss (data not shown). 
Table I: Quantitative densitometry of SNCA in situ hybridization

\begin{tabular}{lccccc}
\hline \multicolumn{7}{c}{ SNCA densitometry R/L ratio } \\
\hline Brain region & PBS $(N=9)$ & Luciferase siRNA $(N=10)$ & SNCA siRNA $(N=I I)$ & P-value: SNCA vs. Luciferase & P-value: SNCA vs. PBS \\
\hline Cortex & $0.92(0.82-0.98)$ & $0.90(0.86-1.00)$ & $0.27(0.20-0.90)$ & 0.036 & $<$ \\
CAI & $1.02(0.98-1.14)$ & $0.97(0.93-1.06)$ & $0.35(0.14-0.54)$ & $<0.001$ & $<.067$ \\
CA2 & $1.02(0.93-1.05)$ & $1.01(0.97-1.15)$ & $0.42(0.19-0.62)$ & $<0.001$ & $<0.001$ \\
CA3 & $1.15(0.99-1.24)$ & $1.09(1.01-1.15)$ & $0.27(0.12-0.71)$ & $<0.001$ & $<0.001$ \\
DG & $1.02(0.99-1.11)$ & $0.99(0.94-1.04)$ & $0.19(0.10-0.68)$ & 0.008 & 0.001 \\
\hline
\end{tabular}

Using densitometry to determine efficacy of SNCA siRNA, SNCA expression in the injected (PBS, luciferase siRNA or SNCA siRNA) right side was compared to the uninjected left side and compared across treatment groups. P-values were derived from Wilcoxon rank sum test and the sample median ( $25^{\text {th }}$ percentile $-75^{\text {th }}$ percentile) is given.

\section{Resilience of SNCA knockdown in mice}

In order to determine the length of time SNCA expression can be repressed following siRNA treatment, we infused SNCA siRNA into the right CA1 of four cohorts. Following 15 days infusion, the first cohort $(2 \mathrm{~W})$ was harvested as above, while the cannulae were removed from the remaining cohorts which were then allowed to age for 1 week ( $2 \mathrm{~W}-1 \mathrm{~W}), 2$ weeks ( $2 \mathrm{~W}-2 \mathrm{~W})$, or three weeks ( $2 \mathrm{~W}-$ $3 \mathrm{~W}$ ) post-infusion. One cannula in the $2 \mathrm{~W}-3 \mathrm{~W}$ group was loose at the end of the study. This mouse, represented by a triangle, was included in the data analysis for Figure 3. Following in situ for SNCA, we observed approximately $60 \%$ knockdown in SNCA expression in the right CA1 and cortex compared to the uninjected left side (Figure 3) which replicated our previous experiments. Additionally, similar SNCA reductions were observed in the right CA2, CA3, and dentate gyrus of mice treated with SNCA siRNA (data not shown). SNCA levels remained qualitatively reduced 1 week post-infusion in the dentate gyrus (data not shown) and 2 weeks post-infusion in the CA1 (Figure 3A), CA2, CA3 (data not shown), and cortex (Figure 3B). By three weeks post-infusion, SNCA levels in the cortex (Figure 3B), CA2, CA3, and dentate gyrus (data not shown) of the siRNA infused side approached control levels. SNCA levels in the right CA1 (Figure 3A), the site of injection, remained noticeably reduced when compared to the uninjected control side through three weeks postinfusion. As in the earlier studies, we saw no impact of SNCA siRNA on the levels of SNCB at any timepoint (Figure 3).

The use of naked siRNAs in the brain has recently been shown be effective against endogenous murine amyloid precursor protein (APP) [25], dopamine transporter (DAT), serotonin transporter (SERT) [26-28], and mutant human huntingtin [29]. The use of RNAi to reduce endogenous $\alpha$-synuclein expression was demonstrated in SHSY5Y cells as well as the impact of silencing on dopamine homeostasis and response to mitochondrial toxins in vitro [30]. Our study presents the first successful in vivo use of stabilized naked siRNA against endogenous SNCA and also demonstrates that a close homologue of the target gene, SNCB, was not altered by RNA interference with naked siRNA in the brain. This analysis of $S N C B$ is particularly important in demonstrating the specificity of the SNCA siRNA silencing, and in showing that an increase in $S N C B$ expression does not compensate for a reduction in its homologue, SNCA. Furthermore, our study also demonstrates that knockdown of SNCA lasted for up to three weeks post infusion, in the CA1, and that the effect was not limited to the hippocampus, the immediate site of delivery, but also diffused into the cortex.

While this study focused on SNCA knockdown in the hippocampus for technical practicalities, it would be of considerable interest to determine if SNCA siRNA would be efficacious in the $\mathrm{SN}$, given its importance in PD. Future work aimed at SN delivery and at silencing SNCA in transgenic mouse models for human $\alpha$-synucleinopathy or toxin models that develop PD like pathology will further enhance our knowledge on the applicability of naked siRNA in the brain and importantly on the suitability of RNA interference of SNCA as a future therapeutic target.

\section{Conclusion}

In this study we have characterized naked siRNA duplexes that actively reduce endogenous SNCA mRNA in vitro and in vivo. Following in vitro evaluation of nine siRNAs to assess efficacy, specificity and stability, we selected a candidate (Mayo8S2) for in vivo testing. After modification to complement the murine sequence (Mayo8S2M), we show that direct infusion of our candidate siRNA into the hippocampi of adult mice resulted in a resilient reduction in the murine SNCA transcript level around the site of infusion as well as in more distant sites. This approach will now facilitate a variety of in vivo experiments to temporally dissect the impact of SNCA up-regulation, aggregation and Lewy-like pathology, in cellular toxicity and neurodegeneration. While considerable work is still needed to optimize delivery, distribution profiles, and stability of the siRNA before this technique could be applied in the clinic, our study provides the foundation for such 
studies and offers hope that this technique may eventually translate into a neuroprotective therapy for $\alpha$-synucleinopathies, including PD, DLB and MSA.

\section{Competing interests}

DB, IT, KC, RB, RKP are employees of Alnylam Pharmaceuticals which is developing therapeutics based on RNA interference. DMM reports a provisional application for patent under 37 CFR $\$ 1.53$ (c) DMM reports a provisional application for patent entitled "Method of Treating Neurodegenerative Disease". Less than $\$ 10,000$ has been awarded to date. DMM also reports provisional applications for patents entitled "Parkinson's Disease-Related Disease Compositions and Methods" and "Predicting Parkinson's Disease", for which no monies have been awarded to date.

\section{Authors' contributions}

JL designed and managed the in vivo studies, and wrote the manuscript. HM performed in situ analysis and co-wrote the manuscript. DB led the siRNA development and conceptually contributed to the studies. AH performed the in vitro studies, co-wrote the manuscript, and performed the statistical analysis of the in vitro data. $\mathrm{CZ}$ and $\mathrm{ZH}$ performed surgery prep, surgeries, and animal care. SL, AB, $\mathrm{SO}, \mathrm{KH}, \mathrm{CK}$ performed RNA and protein analysis. IT, KC, $\mathrm{RB}$, and RKP participated in the conceptual and technical development of the siRNA. MH and JC performed the statistical analysis of the in vivo data. DMM contributed to the conceptual design. MJF designed and managed the in vitro studies and significantly edited the manuscript.

\section{Additional material}

\section{Additional file 1}

Complementary positions of the nine siRNA reagents (Mayo 1-Mayo 9) in relation to the full length SNCA transcript. [NM_000345.2 - longer transcript (isoform NACP140)]. Translation start and stop codons are shown in bold.

Click here for file

[http://www.biomedcentral.com/content/supplementary/1750-

1326-3-19-S1.doc]

\section{Additional file 2}

Immunoblot analysis of in vitro screening of SNCA siRNA in BE(2) M17 human neuroblastoma cells. (A) A typical immunoblot showing EGFP and $\alpha$-tubulin immunoreactivities. Cells were transfected with either pEGFP-C1 (vector) or pEGFP-NACP ( $\alpha$-syn) and one of the Mayo1-9 siRNA reagents or siRNAMr. The three rightmost lanes are no-siRNA controls and an untransfected culture. The conjugated EGFP and $\alpha$-synuclein product (EGFP/NACP) is retarded by the additional 140 amino acids encoded by the SNCA cDNA. (B) Densitometric analysis of combined data from four blots expressed as a fold value of the no-siRNA control according to EGFP: $\alpha$-tubulin ratio. ${ }^{*} p<0.001, t$-test, Welch's modified t-test was used when variances differed.

Click here for file

[http://www.biomedcentral.com/content/supplementary/17501326-3-19-S2.doc]

\section{Additional file 3}

Silencing of endogenous $\alpha$-synuclein in vitro. (A) qRT-PCR of endogenous SNCA transcript from RNA preparations from cells treated with 50 $n M$ siRNAs (Mayo 2, 7, 8, 9, siRNAMr) for $24 \mathrm{~h}$. Each sample was assayed in quadruplicate, and expressed as a fold change from the untransfected control. ${ }^{*} p<0.05$ t-test, Welch's modified $t$-test was used when variances differed. Error bars $=$ SEM. (B) A typical immunoblot of cell extracts following $24 \mathrm{~h}$ transfection with $50 \mathrm{nM}$ siRNA. The control is treated with transfection reagent alone. The position of a $16 \mathrm{kDa}$ marker (lysozyme) is indicated. (C) Densitometric analysis of four independent experiments demonstrates significant reduction in the $\alpha$-synuclein immunoreactivity (IR). ${ }^{*} p<0.05 ;{ }^{* *} p<0.01$ in $t$-test, Welch's modified $t$-test was used when variances differed. Error bars $=$ SEM. Click here for file

[http://www.biomedcentral.com/content/supplementary/17501326-3-19-S3.doc]

\section{Additional file 4}

Target specificity of candidate siRNA molecules. (A) RNA preparations from cells treated for $24 \mathrm{~h}$ with $50 \mathrm{nM}$ Mayo 2 were analyzed by qRTPCR. Although SNCA and SNCB diverge by only four bases within the Mayo2 sequence, silencing is specific to SNCA only. (B and C) Co-transfection studies in cells demonstrate that Mayo2 is active against both human and mouse SNCA, but human specific Mayo7 and Mayo8 do not silence mouse SNCA expression. Error bars = SEM, calculated from three independent assays.

Click here for file

[http://www.biomedcentral.com/content/supplementary/17501326-3-19-S4.doc]

\section{Additional file 5}

Stabilization of siRNAs was achieved by chemical modifications as shown below.

Click here for file

[http://www.biomedcentral.com/content/supplementary/17501326-3-19-S5.doc]

\section{Additional file 6}

Species specificity of mouse and human SNCA siRNA. (A) A typical immunoblot of total protein extracts from cells co-transfected with plasmids conferring expression of EGFP (V; vector) or EGFP-NACP $(H=$ human $\alpha$-synuclein; $M=$ mouse $\alpha$-synuclein) alone (control) or with 50 $n M$ of either Mayo8S2 or Mayo 8S2M siRNA. A reprobe of the blot with $\alpha$-tubulin antibody was used to equalize loading levels. (B) Densitometric analysis of three independent assays demonstrates that silencing of SNCA expression by Mayo8S2 is human specific, and by Mayo8S2M is mouse specific. $p<0.01, t$-test, Welch's modified $t$-test was used when variances differed. Error bars $=$ SEM. *

Click here for file

[http://www.biomedcentral.com/content/supplementary/17501326-3-19-S6.doc]

\section{Acknowledgements}

This work was funded by the Michael J. Fox Foundation (to J.L., D.B., and M.J.F.) and the Mayo Foundation (to J.L. and M.J.F.). We thank Richard Crook and Zeshan Ahmed for help with the figures and Faith Conkle, Deb Maloy and the animal care staff for ensuring animal welfare. 


\section{References}

I. Polymeropoulos MH, Lavedan C, Leroy E, Ide SE, Dehejia A, Dutra A, Pike B, Root H, Rubenstein J, Boyer R, Stenroos ES, Chandrasekharappa S, Athanassiadou A, Papapetropoulos T, Johnson WG, Lazzarini AM, Duvoisin RC, Di lorio G, Golbe LI, Nussbaum RL: Mutation in the alpha-synuclein gene identified in families with Parkinson's disease. Science 1997, 276:2045-2047.

2. Kruger R, Kuhn W, Muller T, Woitalla D, Graeber M, Kosel S, Przuntek H, Epplen JT, Schols L, Riess O: Ala30Pro mutation in the gene encoding alpha-synuclein in Parkinson's disease. Nat Genet 1998, I 8:106-108.

3. Zarranz JJ, Alegre J, Gómez-Esteban JC, Lezcano E, Ros R, Ampuero I, Vidal L, Hoenicka J, Rodriguez O, Atarés B, Llorens V, Gomez Tortosa E, del Ser T, Muñoz DG, de Yebenes JG: The new mutation, E46K, of alpha-synuclein causes Parkinson and Lewy body dementia. Ann Neurol 2004, 55: 164-173.

4. Spillantini MG, Schmidt ML, Lee VM, Trojanowski JQ, Jakes R, Goedert M: Alpha-synuclein in Lewy bodies. Nature 1997, 388:839-840.

5. Singleton $A B$, Farrer $M$, Johnson J, Singleton A, Hague S, Kachergus J, Hulihan M, Peuralinna T, Dutra A, Nussbaum R, Lincoln S, Crawley A, Hanson M, Maraganore D, Adler C, Cookson MR, Muenter M, Baptista M, Miller D, Blancato J, Hardy J, Gwinn-Hardy K: alphaSynuclein locus triplication causes Parkinson's disease. Science 2003, 302:84I.

6. Gwinn-Hardy K, Mehta ND, Farrer M, Maraganore D, Muenter $M$, Yen SH, Hardy J, Dickson DW: Distinctive neuropathology revealed by alpha-synuclein antibodies in hereditary parkinsonism and dementia linked to chromosome 4p. Acta Neuropathol 2000, 99:663-672.

7. Muenter MD, Forno LS, Hornykiewicz O, Kish SJ, Maraganore DM, Caselli RJ, Okazaki H, Howard FM Jr, Snow BJ, Calne DB: Hereditary form of parkinsonism-dementia. Ann Neurol 1998, 43:768-781.

8. Farrer M, Kachergus J, Forno L, Lincoln S, Wang DS, Hulihan M, Maraganore D, Gwinn-Hardy K, Wszolek Z, Dickson D, Langston JW: Comparison of kindreds with parkinsonism and alpha-synuclein genomic multiplications. Ann Neurol 2004, 55: I 74- 179.

9. Chartier-Harlin MC, Kachergus J, Roumier C, Mouroux V, Douay X, Lincoln S, Levecque C, Larvor L, Andrieux J, Hulihan M, Waucquier N, Defebvre L, Amouyel P, Farrer M, Destée A: Alpha-synuclein locus duplication as a cause of familial Parkinson's disease. Lancet 2004, 364: I 167-1 169.

10. Ibanez P, Bonnet AM, Debarges B, Lohmann E, Tison F, Pollak P, Agid $Y$, Durr A, Brice A: Causal relation between alpha-synuclein gene duplication and familial Parkinson's disease. Lancet 2004, 364: ||69-117|.

II. Fuchs J, Nilsson C, Kachergus J, Munz M, Larsson EM, Schüle B, Langston JW, Middleton FA, Ross OA, Hulihan M, Gasser T, Farrer MJ: Phenotypic variation in a large Swedish pedigree due to SNCA duplication and triplication. Neurology 2007, 68:916-922.

12. Nishioka K, Hayashi S, Farrer MJ, Singleton AB, Yoshino H, Imai H, Kitami T, Sato K, Kuroda R, Tomiyama H, Mizoguchi K, Murata M, Toda T, Imoto I, Inazawa J, Mizuno Y, Hattori N: Clinical heterogeneity of alpha-synuclein gene duplication in Parkinson's disease. Ann Neurol 2006, 59:298-309.

13. Ikeuchi T, Kakita A, Shiga A, Kasuga K, Kaneko H, Tan CF, Idezuka J, Wakabayashi K, Onodera O, Iwatsubo T, Nishizawa M, Takahashi H, Ishikawa A: Patients Homozygous and Heterozygous for SNCA Duplication in a Family With Parkinsonism and Dementia. Arch Neurol 2008, 65:514-519.

14. Ahn TB, Kim SY, Kim JY, Park SS, Lee DS, Min HJ, Kim YK, Kim SE, Kim JM, Kim HJ, Cho J, Jeon BS: alpha-Synuclein gene duplication is present in sporadic Parkinson disease. Neurology 2008, 70:43-49.

15. Miller DW, Hague SM, Clarimon J, Baptista M, Gwinn-Hardy K, Cookson MR, Singleton AB: Alpha-synuclein in blood and brain from familial Parkinson disease with SNCA locus triplication. Neurology 2004, 62: 1835-1838.

16. Ross OA, Gosal D, Stone JT, Lincoln SJ, Heckman MG, Irvine GB, Johnston JA, Gibson JM, Farrer MJ, Lynch T: Familial genes in sporadic disease: common variants of alpha-synuclein gene associate with Parkinson's disease. Mech Ageing Dev 2007, I 28:378-382.

17. Maraganore DM, de Andrade M, Elbaz A, Farrer MJ, loannidis JP, Krüger R, Rocca WA, Schneider NK, Lesnick TG, Lincoln SJ, Hulihan
MM, Aasly JO, Ashizawa T, Chartier-Harlin MC, Checkoway H, Ferrarese C, Hadjigeorgiou G, Hattori N, Kawakami H, Lambert JC, Lynch T, Mellick GD, Papapetropoulos S, Parsian A, Quattrone A, Riess O, Tan EK, Van Broeckhoven C, Genetic Epidemiology of Parkinson's Disease (GEO-PD) Consortium: Collaborative analysis of alpha-synuclein gene promoter variability and Parkinson disease. Jama 2006, 296:66 I-670.

18. Winkler S, Hagenah J, Lincoln S, Heckman M, Haugarvoll K, LohmannHedrich K, Kostic V, Farrer M, Klein C: alpha-Synuclein and Parkinson disease susceptibility. Neurology 2007, 69: I745-I750.

19. Chiba-Falek O, Nussbaum RL: Effect of allelic variation at the NACP-Repl repeat upstream of the alpha-synuclein gene (SNCA) on transcription in a cell culture luciferase reporter system. Hum Mol Genet 2001, 10:3101-3109.

20. Chiba-Falek O, Touchman JW, Nussbaum RL: Functional analysis of intra-allelic variation at NACP-Repl in the alpha-synuclein gene. Hum Genet 2003, I I 3:426-43I.

21. Fire A, Xu S, Montgomery MK, Kostas SA, Driver SE, Mello CC: Potent and specific genetic interference by double-stranded RNA in Caenorhabditis elegans. Nature 1998, 391:806-81 I.

22. Elbashir SM, Lendeckel W, Tuschl T: RNA interference is mediated by 21 - and 22-nucleotide RNAs. Genes Dev 200I, I5:188-200.

23. Schwarz DS, Tomari Y, Zamore PD: The RNA-induced silencing complex is a Mg2+-dependent endonuclease. Curr Biol 2004 , | 4:787-79|.

24. Paxinos G, Franklin K: The Mouse Brain in Stereotaxic Co-ordinates 2nd edition. San Diego, CA.: Academic Press; 200I.

25. Senechal Y, Kelly PH, Cryan JF, Natt F, Dev KK: Amyloid precursor protein knockdown by siRNA impairs spontaneous alternation in adult mice. I Neurochem 2007, I 02:1928-1940.

26. Hoyer D, Thakker DR, Natt F, Maier R, Huesken D, Muller M, Flor P $H$ VDP, Schmutz M, Bilbe G, Cryan JF: Global down-regulation of gene expression in the brain using RNA interference, with emphasis on monoamine transporters and GPCRs: implications for target characterization in psychiatric and neurological disorders. J Recept Signal Transduct Res 2006, 26:527-547.

27. Thakker DR, Natt F, Husken D, Maier R, Muller M, Putten H van der, Hoyer D, Cryan JF: Neurochemical and behavioral consequences of widespread gene knockdown in the adult mouse brain by using nonviral RNA interference. Proc Natl Acad Sci USA 2004, I 01 : 17270-17275.

28. Thakker DR, Natt F, Husken D, Putten $H$ van der, Maier R, Hoyer D, Cryan JF: siRNA-mediated knockdown of the serotonin transporter in the adult mouse brain. Mol Psychiatry 2005, I 0:782-789.

29. DiFiglia M, Sena-Esteves M, Chase K, Sapp E, Pfister E, Sass M, Yoder J, Reeves P, Pandey RK, Rajeev KG, Manoharan M, Sah DW, Zamore $\mathrm{PD}$, Aronin N: Therapeutic silencing of mutant huntingtin with siRNA attenuates striatal and cortical neuropathology and behavioral deficits. Proc Natl Acad Sci USA 2007, I 04: | 7204-| 7209.

30. Fountaine TM, Wade-Martins R: RNA interference-mediated knockdown of alpha-synuclein protects human dopaminergic neuroblastoma cells from $\mathrm{MPP}(+)$ toxicity and reduces dopamine transport. J Neurosci Res 2007, 85:35I-363.

Publish with Bio Med Central and every scientist can read your work free of charge

"BioMed Central will be the most significant development for disseminating the results of biomedical research in our lifetime. "

Sir Paul Nurse, Cancer Research UK

Your research papers will be:

- available free of charge to the entire biomedical community

- peer reviewed and published immediately upon acceptance

- cited in PubMed and archived on PubMed Central

- yours - you keep the copyright

BioMedcentral 